\title{
Highly efficient carbene and polycarbene catalysis of the transesterification reaction
}

\section{Konstantin A. Marichev, ${ }^{a}$ Nikolai I. Korotkikh, ${ }^{* b}$ Alan H. Cowley, ${ }^{c}$ Vagiz Sh. Saberov, ${ }^{b}$ Nataliya V. Glinyanaya, ${ }^{a}$ Gennady F. Rayenko, ${ }^{a}$ and Oles P. Shvaika ${ }^{a}$}

a The L.M. Litvinenko Institute of Physical Organic and Coal Chemistry, Ukrainian Academy of Sciences, 50 Kharkiv road, Kiev 02160, Ukraine

${ }^{b}$ The Institute of Organic Chemistry, Ukrainian Academy of Sciences, 5, Murmanskaya Str., Kyiv-94, 02660, Ukraine

' Department of Chemistry, The University of Texas at Austin, 1 University Station A5300, Austin, Texas 78712-0165, U.S.A.

Email: nkorotkikh@ua.fm

\section{Received 01-27-2017}

Accepted 03-12-2017

Published on line 06-27-2017

\section{Abstract}

Highly efficient carbene and polycarbene catalysis of the transesterification reaction of ethyl benzoate in methanol has been observed and results in values of TON as high as 4000-6150 at a molar ratio of ester to methanol of 1:18 at room temperature. The most effective catalysts were found to be the individual carbenes or in situ generated carbenes, namely adamantyl and aromatic substituted cyclic compounds and polymeric carbenes. None of the reactions requires the use of molecular sieves. The polymeric imidazol-2-ylidene catalyst was used for the efficient production of biodiesel fuel from sunflower oil.<smiles>CCOC(=O)c1ccccc1</smiles>

TON 6150 TON 4300<smiles>CC1[C]N([Al]C(C)C)C=C1</smiles>

$\mathrm{A}=-\mathrm{CH}_{2} \mathrm{C}_{6} \mathrm{H}_{4} \mathrm{CH}_{2}-p-$

TON 4000

Keywords: Carbenes, transesterification, catalysis, efficiencies 


\section{Introduction}

The transesterification reaction is one of the mildest and most effective methods for the preparation of esters. ${ }^{1}$ However, the traditional catalysts are either insufficiently effective due to their basic nature or cause corrosion of the metallic equipment (inorganic acids). Since stable carbenes are highly basic compounds ( $\mathrm{pK}_{\mathrm{a}}$ 21-28) they have also been suggested as catalysts for the transesterification reaction. ${ }^{2-8}$ The latter reaction is typically carried out at room temperature in the presence of 0.5-5.0 mol\% of carbenes and molecular sieves. The efficiencies of the catalysts can be estimated on the basis of the values of TON and TOF. TON is a turnover number that means a number of catalytic cycles made (the ratio of a mol number of the product to a mol number of the catalyst). TOF is a turnover frequency that means a number of catalytic cycles per a unit of time, the most often per one hour (TON per a unit of time). In the case of reactions that are catalysed by imidazol-2-ylidenes and their 4,5-dihydro analogues, the TON values typically fall in the range of 20-60, TOF $30-220 \mathrm{~h}^{-1}$. $^{2}$ However, larger values of 200 and 2300 respectively have been observed for the reactions of vinyl esters due to the irreversibility of the acetaldehyde release process. ${ }^{4}$

The transesterification reaction serves as an important tool for the production of biodiesel fuel. In the latter case the reaction is carried out in an excess of alcohol. To the best of our knowledge, there has only been one attempt to carry out a similar catalytic process using carbenes on a model compound. ${ }^{3}$ In this paper the transesterification of methyl benzoate with ethanol and isopropanol in a 1:20 molar ratio was carried out in the presence of 3.6-4.4 mol\% of 1,3-disubstituted imidazol-2-ylidenes and resulted in $79-85 \%$ yields of ethyl esters (TON 17-19, TOF $1 \mathrm{~h}^{-1}$ ).

The catalytic activities of other classes of stable carbene have not been studied yet.

The goal of the present work was to study the catalytic properties of a variety of types of stable carbenes for use in transesterification reactions.

It was particularly important taking into account moderate or low efficiences of carbenes in many other organic reactions (in most cases TON is no more than 100). ${ }^{9,10}$

\section{Results and Discussion}

\section{Preparation of carbenes and precarbenes}

Ethyl benzoate was used as the model compound for the transformation to methyl benzoate in the presence of a catalyst in methanol solution (Scheme 1). The stable carbenes 1-11 were used as catalysts for this reaction (Schemes 1 and 2), and were generated in situ from the corresponding azolium salts $\left(\mathrm{BH}^{+} \mathrm{X}^{-}\right)$, or alternatively used as individual compounds $(\mathbf{1} \mathbf{a}, \mathbf{2} \mathbf{d}, \mathbf{3 c}, \mathbf{7})$. The requisite compounds were the monocarbenes 1-6, the biscarbenes 7,8 and the polycarbenes 9-11. In alcohol solutions all of these compounds are in equilibrium with alkoxyazolines and $\mathrm{H}$-complexes of carbenes (see, for example, the equilibrium $1 \rightleftarrows 1 \mathrm{~A} \rightleftarrows 1 \mathrm{~B}$ in Scheme 3).

The requisite carbenes $\mathbf{1 - 1 1}$ were generated in situ using the appropriate precarbenes $\left(\mathrm{BH}^{+} \mathrm{X}\right)$ and potassium methoxide in anhydrous methanol solution. The corresponding organic perchlorate salts were used as precarbenes.

For comparison purposes the catalysis was also studied with ammonium (12) and phosphonium (13) methoxides which together with sodium methoxide can clear up the role of alkoxide ions in catalysis. However, it should be noted that the first compound can exist in equilibrium with ammonium ylides, ${ }^{11}$ as can the latter compound with the appropriate phosphorane 13A (Scheme 3). 
PhCOOEt $\underset{-\mathrm{MtOH}}{\stackrel{\mathrm{MeOH}, \mathrm{cat}}{\longrightarrow}}$ PhCOOMe<smiles>[R]C1=C([R])N([R])CN1[R]</smiles>

1a $\mathrm{R}=t-\mathrm{Bu}, \mathrm{Ar}=p-\mathrm{BrC}_{6} \mathrm{H}_{4} ; \mathbf{1 b} \mathrm{R}=p-\mathrm{BrC}_{6} \mathrm{H}_{4} \mathrm{CH}_{2}, \mathrm{Ar}=p-\mathrm{BrC}_{6} \mathrm{H}_{4} ; \mathbf{2 a} \mathrm{R}=\mathrm{Bn}, \mathrm{R}^{\prime}=\mathrm{H} ; \mathbf{2 b} \mathrm{R}=1-\mathrm{Ad}, \mathrm{R}^{\prime}=\mathrm{H} ; \mathbf{2 c} 1-\mathrm{Ad}$, $\mathrm{R}^{\prime}=\mathrm{Ph} ; \mathbf{2 d} \mathrm{R}=\mathrm{dbep}, \mathrm{R}^{\prime}=\mathrm{H}$; $3 a \mathrm{R}=\mathrm{Me}, \mathbf{3 b} \mathrm{R}=\mathrm{Bn}, \mathbf{3 c} \mathrm{R}=1$ 1-Ad. dbep = 2,6-dibenzhydryl-4-ethylphenyl

Scheme 1. Monocarbene catalysts for transesterification of ethyl benzoate in methanol

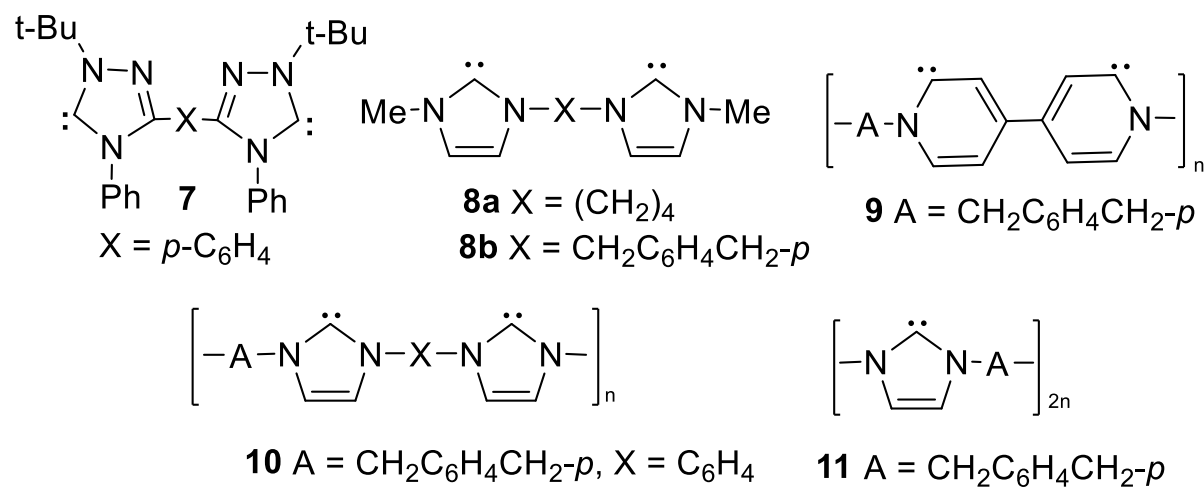

Scheme 2. Biscarbene and polycarbene catalysts for transesterification of ethyl benzoate in methanol

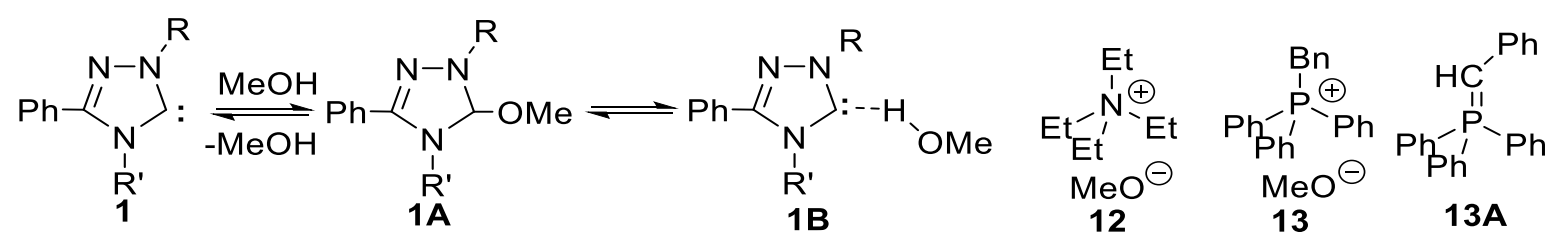

Scheme 3. Equilibria of 1,2,4-triazol-5-ylidenes in methanol. Ammonium and phosphonium methoxides as catalysts for transesterification of ethyl benzoate in methanol

Methods for the preparation of precarbenes for compounds 1-7 are well known and are indicated in the Supporting Information (SI). ${ }^{12-28}$ The known carbenes $\mathbf{1 a}, \mathbf{2 d}, \mathbf{3 c}, \mathbf{7}$ were used in an isolated state. Methods for their preparation are also given in the SI.

The structures of the carbenes $\mathbf{1 a}, \mathbf{2} \mathbf{d}, \mathbf{3 c}, \mathbf{7}$ were confirmed on the basis of single crystal X-ray diffraction studies. $^{12,15,20,22,23,25}$

The bisazolium salts $\mathbf{8 a}, \mathbf{b} \cdot \mathbf{2} \mathbf{H X}$ were synthesized by quaternization of 1,4-di-(1-imidazolyl)butane $\mathbf{8 A}$ or p-xylylenedi-(1-imidazole) 8B with dimethyl sulfate, followed by the anion exchange to form the perchlorate (Scheme 4). The polymeric salts for carbenes 9-11 were obtained by quaternization of 4,4'-dipyridyl, $p$-bis-(1imidazolyl)benzene $\mathbf{1 0 A}$ and $p$-xylylenedi-(1-imidazole) $\mathbf{8 B}$, respectively, with $p$-xylylene dichloride (for compounds $\mathbf{1 0} \cdot \mathbf{2} \mathrm{HClO}_{4}$ and $\mathbf{1 1} \cdot \mathbf{2} \mathrm{HClO}_{4}$ see Scheme 5). Experimental procedures for the preparation of compounds $\mathbf{8 a}, \mathbf{b} \cdot \mathbf{2} \mathrm{HClO}_{4}, \mathbf{9 - 1 1} \cdot \mathbf{2} \mathrm{HClO}_{4}$ are presented below. 


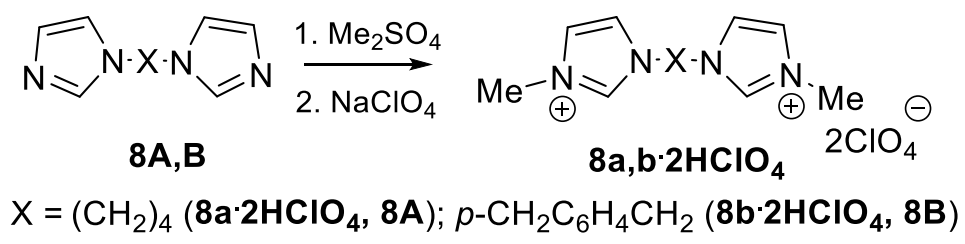

Scheme 4. Synthesis of bisimidazolium salts $8 \mathbf{a}, \mathbf{b} \cdot \mathbf{2} \mathrm{HClO}_{4}$
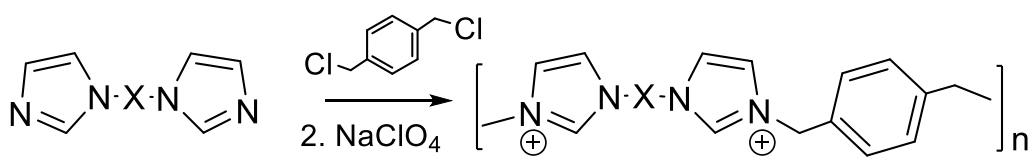

10A,11A

$10,11 \cdot 2 \mathrm{HClO}_{4} \quad 2 \mathrm{ClO}_{4}{ }^{\ominus}$

$X=p-\mathrm{C}_{6} \mathrm{H}_{4}\left(10 \cdot 2 \mathrm{HClO}_{4}, 10 \mathrm{~A}\right) ; p-\mathrm{CH}_{2} \mathrm{C}_{6} \mathrm{H}_{4} \mathrm{CH}_{2}\left(11 \cdot 2 \mathrm{HClO}_{4}, 11 \mathrm{~A}\right)$

Scheme 5. Synthesis of polymeric imidazolium salts $\mathbf{1 0}, \mathbf{1 1} \cdot \mathbf{2} \mathrm{HClO}_{4}$.

The compositions of compounds $9,10 \cdot 2 \mathrm{HClO}_{4}, \mathbf{1 0 A}, \mathbf{1 1 A}$ and $11 \mathrm{a}, \mathbf{b} \cdot \mathbf{2} \mathrm{HClO}_{4}$ have been confirmed by elemental analysis and the structures by ${ }^{1} \mathrm{H}$ NMR spectroscopy and liquid chromatography. The characteristic signal of meso-proton of the imidazole ring ( $\delta 8.37 \mathrm{ppm})$ was observed in the ${ }^{1} \mathrm{H} N M R$ spectra of compound 10A. The ${ }^{1} \mathrm{H}$ NMR spectrum of compound 11A shows the characteristic signals of the methylene ( $\left.\delta 5.10 \mathrm{ppm}\right)$ and the meso-proton of the imidazole ring ( $\left.\delta \mathrm{C}^{2} \mathrm{H} 7.52 \mathrm{ppm}\right)$.

Compound $\mathbf{1 1} \cdot \mathbf{H C l O}_{4}$ is easily soluble in polar organic solvents, such as dimethylformamide, dimethylsulfoxide and insoluble in other organic solvents. According to the liquid chromatography data the polymer $\mathbf{1 1} \cdot 2 \mathrm{HClO}_{4}$ has a narrow molecular weight distribution $\left(\mathrm{M}_{\mathrm{w}} 68800 ; \mathrm{M}_{\mathrm{n}} 63100 ; \mathrm{M}_{\mathrm{w}} / \mathrm{M}_{\mathrm{n}}=1.09 ; \mathrm{n}_{\text {aver }}=\right.$ 257). The low degree of polydispersity of the polymer is also confirmed by the narrow single signals in the ${ }^{1} \mathrm{H}$ NMR spectrum. Particularly, there are narrow signals of methylene ( $\delta 5.44 \mathrm{ppm}$ ), aromatic protons ( $\delta 7.50-$ $7.78 \mathrm{ppm})$ and meso-protons $\left(\mathrm{C}^{2} \mathrm{H}\right)$ of the imidazolium ring $(\delta 9.37 \mathrm{ppm})$.

It should be noted that the polymeric salt $\mathbf{1 0} \cdot \mathbf{2} \mathbf{H C l O}_{\mathbf{4}}$ has conjugated fragments and a monomeric unit comprises two carbenoid centers unlike the polyxylyleneimidazolium polymer $\mathbf{1 1} \cdot \mathbf{2} \mathbf{H C l O} \mathbf{O}_{4}$ that includes only one carbenoid center in a monomeric unit.

The singlet proton signals for polymeric salts $\mathbf{9} \cdot \mathbf{2} \mathrm{HClO}_{\mathbf{4}}$ and $\mathbf{1 0} \cdot \mathbf{2} \mathbf{H C l O}_{\mathbf{4}}$ are expressed rather clearly. The signals of methylene group ( $\delta 5.95 \mathrm{ppm}$ ), aromatic proton and pyridinium phenylene nuclei $(\delta 7.70-8.73$ ppm) were found in the spectrum of the polymer salt $\mathbf{9} \cdot \mathbf{2} \mathrm{HClO}_{4}$ along with $\mathrm{C}^{2} \mathrm{H}$-signals of the pyridinium nuclei that are shifted downfield $(\delta 9.33$ and $9.47 \mathrm{ppm})$. The signals of meso-protons of salt $10 \cdot 2 \mathrm{HClO}_{4}\left(\mathrm{C}^{2} \mathrm{H}\right)$ is strongly shifted downfield ( $\delta 10.11 \mathrm{ppm}$ ) as compared with bisimidazolium salt $8 \mathbf{a}$ ( $\delta 9.05 \mathrm{ppm}$ ), to a lesser extent, but also shifted downfield the characteristic signals of the methylene ( $\delta 5.58$ ppm) and aromatic protons ( $\delta 7.65-8.44 \mathrm{ppm})$.

\section{Catalytic results}

The overall results of the catalytic transesterification of compounds 1-11 are presented in the Table.

The data in the table revealed that the efficiency of a sodium methoxide in these reactions is minimal (TON 7-17, TOF 8-22 $\mathrm{h}^{-1}$ ). As a consequence a significant concentration of the catalyst and an increase in temperature are necessary for generating high yields of the product under the conditions that were selected for this experiment (the ratio of the reactants was chosen to be 1:9, 0.04 mol\% of the catalyst and $4 \mathrm{~h}$ at room temperature). 
Table. The catalytic properties of carbenes 1-11 and compounds 12 and 13 in the transesterification reaction of ethyl benzoate in methanol solution (molar ratio of reactants $1: 9$ ) at $23^{\circ} \mathrm{C}$

\begin{tabular}{|c|c|c|c|c|c|}
\hline Catalyst & Catalyst loading, (mol\%) & Time, $\mathrm{h}$ & Yield, \% & TON & TOF, $\mathrm{h}^{-1}$ \\
\hline $\mathrm{CH}_{3} \mathrm{ONa}$ & 5.00 & 2.00 & 85 & 17 & 8,5 \\
\hline $\mathrm{CH}_{3} \mathrm{ONa}$ & 2.00 & 0.33 & 14,5 & 7,3 & 21,8 \\
\hline $1 a$ & 0.04 & 4.00 & 7 & 175 & 44 \\
\hline $1 b$ & 0.04 & 4.00 & 9 & 225 & 56 \\
\hline $2 a$ & 0.04 & 4.00 & 65 & 1625 & 406 \\
\hline $2 b$ & 0.04 & 4.00 & 93.5 & 2338 & 584 \\
\hline $2 b$ & $0.01^{a}$ & 4.00 & 35 & 3500 & 875 \\
\hline $2 c$ & 0.04 & 4.00 & 94 & 2350 & 588 \\
\hline $2 c$ & $0.01^{a}$ & 4.00 & 43 & 4300 & 1075 \\
\hline $2 d$ & 0.04 & 4.00 & 0 & 0 & 0 \\
\hline $3 a$ & 0.04 & 4.00 & 72 & 1800 & 450 \\
\hline $3 b$ & 0.04 & 4.00 & 70 & 1750 & 438 \\
\hline $3 c$ & 0.04 & 4.00 & 93,5 & 2338 & 585 \\
\hline $3 c$ & $0.01^{a}$ & 4.00 & 26 & 2600 & 650 \\
\hline $3 c$ & $0.01^{b}$ & 4.00 & 61,5 & 6150 & 1538 \\
\hline 4 & 0.04 & 4.00 & 84 & 2100 & 525 \\
\hline 5 & 0.04 & 4.00 & 88,5 & 2213 & 553 \\
\hline 6 & 0.04 & 4.00 & 90 & 2250 & 563 \\
\hline 7 & 0.04 & 4.00 & 25 & 625 & 156 \\
\hline $8 a$ & 0.04 & 4.00 & 52 & 1300 & 325 \\
\hline $8 b$ & 0.04 & 4.00 & 87 & 2175 & 544 \\
\hline 9 & 0.5 & 4.00 & 94 & 188 & 47 \\
\hline 9 & 0.04 & 4.00 & 84 & 2100 & 525 \\
\hline 10 & 0.5 & 4.00 & 95 & 190 & 48 \\
\hline 10 & 0.04 & 4.00 & 94 & 2350 & 588 \\
\hline 11 & 0.1 & 0.33 & 88 & 880 & 2667 \\
\hline 11 & $0.01^{a}$ & 0.33 & 19 & 1900 & 5758 \\
\hline 11 & $0.01^{a}$ & 4.00 & 40 & 4000 & 1000 \\
\hline 11 & 0.04 & 4.00 & 94 & 2350 & 588 \\
\hline 11 & $0.033^{c}$ & 4.00 & 88 & 2667 & 667 \\
\hline 12 & 0.04 & 4.00 & 46 & 1150 & 288 \\
\hline 13 & 0.04 & 4.00 & 65 & 1575 & 394 \\
\hline
\end{tabular}

${ }^{a}$ The experiment was carried out at the molar ratio ester-methanol 1:18, for $4 \mathrm{~h}$ at room temperature; ${ }^{b}$ with individual carbene $\mathbf{3 c}$; ${ }^{c}$ with sunflower oil. The catalyst loading, TON and TOF are indicated on the basis of one ester group of the oil. 
The efficiency of the triazolylidene catalysts $\mathbf{1 a}, \mathbf{b}, \mathbf{7}$ (either in an individual state or in an situ generated form) was found to be higher than that for sodium methoxide. The carbenes $\mathbf{1 a}$ and $\mathbf{1} \mathbf{b}$ were found to be less active (TON 175-225, TOF 44-56 h-1) than those of the biscarbene 7 (TON 625, TOF $156 \mathrm{~h}^{-1}$ ). It is interesting to note that under identical conditions, the increase in the number of catalytic centers in one molecule of compound 7 relative to that of 1 a resulted in a higher yield of methyl benzoate by almost four times (25\%). In the case of the highly sterically shielded carbene with branched aromatic substituents (2d) the catalytic effect was not evident.

The efficiencies of carbenes $\mathbf{1}$ and $\mathbf{7}$ of the triazole series were found to be significantly inferior to those of carbenes $\mathbf{2 a}$, 3a and $\mathbf{3 b}$ of the imidazole and benzimidazole series (TON 1620-1800, TOF 270-450 $\mathrm{h}^{-1}$ ). Even at loadings of 0.04 mol\% for compounds $\mathbf{2 a}, \mathbf{3 a}$ and $\mathbf{3 b}$ yields of methyl benzoate can be achieved in the region of 65-72\% when exposed to room temperature for 4 hours. However, on the other hand, the arylene substituted biscarbene $\mathbf{8 b}$ exhibited an even higher efficiency (TON 2183, TOF $546 \mathrm{~h}^{-1}$ ), by contrast the biscarbene 8 a with an aliphatic bridge is significantly lower in terms of efficiency (TON 1300, TOF $325 \mathrm{~h}^{-1}$ ).

In the cases of the diaminocarbenes $\mathbf{4}$ and $\mathbf{5}$ and the cycloheptatrienylidene $\mathbf{6}$ the efficiencies were found to be even higher (TON 2100-2250, TOF 525-563 $\mathrm{h}^{-1}$ ) than those for the imidazol-2-ylidene 2a and the benzimidazol-2-ylidenes $\mathbf{3 a}$ and $\mathbf{3} \mathbf{b}$. Overall, the adamantyl substituted imidazol-2-ylidenes $\mathbf{2} \mathbf{b}$ and $\mathbf{2} \mathbf{c}$ and the benzimidazol-2-ylidene 3c were found to achieve the highest levels of efficiency (TON 2338-2350, TOF 584$\left.588 \mathrm{~h}^{-1}\right)$.

The carbenes 9-11 were also found to be highly efficient polymeric catalysts and exhibited high TON values in the range of 2100-2350.

In terms of relative efficiencies RTON represents a TON value that is comparable to that for the reference catalyst (taken as a unit). Under identical experimental conditions, the following series for the efficiencies emerged for the carbene catalysts that were examined: $\mathbf{2 d}(0)<\mathbf{1 a}(1,0)<\mathbf{1 b} 1,5)<7(1,8)<\mathbf{8 a}(3,7)<\mathbf{8 b}$ $(6,2)<\mathbf{9}(6,0)<\mathbf{1 0}(6,7)<\mathbf{2 a}(9,3)<\mathbf{3 b}(10,0)<3 \mathbf{a}(10,3)<\mathbf{4}(12,0)<\mathbf{5}(12,6)<\mathbf{6}(12,9)<\mathbf{3 c}=\mathbf{2 b}(13,3)<\mathbf{2 c}=$ $11(13,4)$.

An additional increase in efficiency was observed for the carbenes (TON 2600-4300 and TOF 650-1075 $\mathrm{h}^{-1}$ ) using a 0.01 mol\% loading and a ratio of the reagents of 1:18. In this case a series of efficiencies was evident from the values of TON and TOF, in $h^{-1}: \mathbf{3 c}(2600,650)<\mathbf{2 b}(3500,875)<11(4000,1000)<2 c(4300$, 1075)

Compounds $\mathbf{2 b}, \mathbf{c}, \mathbf{3 c}, \mathbf{1 1}$ exhibited the highest catalytic efficiencies for the transesterification reaction. Moreover, in this case the method does not require the use of molecular sieves to produce high yields of the end products. Among the individual carbenes $(\mathbf{1} a, \mathbf{2} d, \mathbf{3 c}, \mathbf{7})$ compound $\mathbf{3 c}$ was found to have the highest efficiency (TON 6150, TOF $1538 \mathrm{~h}^{-1}$ ).

The following conclusions can be made with respect to the different factors that influence the catalytic efficiencies.

1) The largest influence on the catalytic efficiencies of the carbenes is exhibited by carbenes that feature $N$ adamantyl- and $\mathrm{N}$-aromatic groups (even if they are not connected to a heterocyclic nucleus such as $p$ xylylene) (2b, c, 3c, 4, 5, 8b, 10, 11). The carbocyclic aromatic carbene $\mathbf{6}$ is also very efficient. In some cases the TON values can be very large (for $3 c$ up to 6150 cycles).

The high effect of adamantyl substituted compounds $\mathbf{2 b} \mathbf{b}, \mathbf{3 c}, \mathbf{4}, \mathbf{5}$ can be explained by their largest nucleophilicities. For compounds $\mathbf{8 b}, \mathbf{1 0}, \mathbf{1 1}$ not only carbene centers can play an important role but also their ylidic forms (being in an equilibrium).

2) The steric shielding of carbenes (for example, by the use of adamantyl groups) increases the efficiency of the catalysis. It should be recalled, however, that some results depend on the extent of steric shielding. For 
example, carbene $\mathbf{2 d}$ has a buried volume of $\% \mathrm{~V}_{\text {bur }} 53 \%$ (for the evaluation of analogues) ${ }^{29,30}$ but, by contrast, does not show a notable catalytic effect.

3) Individual carbenes are considerably more efficient than those of the in situ generated compounds (in the case of carbene $3 c$ by 2,6 times). Furthermore, in the latter case the efficiency is also dependent on the method that was employed for carbene generation.

The foregoing results indicate that catalyst $\mathbf{1 1}$ would be one of the best choices for the transesterification reaction of plant oils (esters of fatty acids and glycerol). In fact, when the catalytic green process was carried out on sunflower oil in the presence of compound 11 [0,1 mol\% or $0.033 \mathrm{~mol} \%$ for one ester function] this catalyst worked with high efficiency (TON 2667, TOF $667 \mathrm{~h}^{-1}$ ) and afforded an $88 \%$ yield of the distilled colorless mixture of methyl esters of fatty acids that are predominantly linoleic (75\%) and oleic (23\%), that in turn can be used in industry for the production of e.g. perfume additives or biodiesel fuel. In the latter case, only technical oils should be used (from e.g. palm, rapeseed, algae, etc.).

It should be noted that until now many catalysts have been proposed for the preparation of biodiesel fuel (as reviews see, for example, the papers ${ }^{31-34}$ ). Among them special attention was paid to guanidine derivatives (see also ${ }^{35-38}$ ), which having basicities close to carbenes do not form soaps during the reaction and their catalytic efficiencies are close to those for sodium hydroxide and methoxide (for 1,5,7-triazabicyclo[4.4.0]dec5-ene TBD TON is no more than 270 at $70{ }^{\circ} \mathrm{C}, 1 \mathrm{~mol} \%$ of a catalyst, the molar ratio of rapeseed oil : methanol is 1:2.3). As can be seen from the data obtained in the present work carbenes are considerably more efficient (TON 2667 at room temperature, 0,1 mol\% of a catalyst, the molar ratio of sunflower oil : methanol is 1:20).

The mechanism of the catalysis of the transesterification reaction by carbenes has not yet been studied in detail. ${ }^{27}$ However, the low efficiency of sodium methoxide in the reaction indicates that the role of the carbene catalyst is not limited by the reaction of alkoxide ions with the ester. The ammonium (12) and phosphonium (13) alkoxides that are generated from the corresponding salts are significantly more effective as stronger bases (TON 1150, 1575 and TOF 288, $394 \mathrm{~h}^{-1}$, respectively) than sodium methoxide (probably due to their ylidic forms playing a part in the reaction). As a consequence, the phosphonium ylide, easily obtained from salt 13, is more effective than the ammonium ylide from salt $\mathbf{1 2}$. However, carbenes 2-6, 8b, 9-11 are significantly more efficient than those of the ammonium and phosphonium catalysts derived from salts 12 and 13. The increase of the efficiencies of the heterocyclic carbene catalysts relative to those of the onium ylides from 12 and 13 points to an important role of the carbene centers for catalysis, particularly multiplet ones to activate the ester molecules.

Several possible versions of the mechanism have been discussed and presented. Examples include the work described in research reports ${ }^{39,40}$ or in monographs ${ }^{9,10}$. However, a common feature of these mechanisms is the participation of carbenes that are connected to alcohols by means of $\mathrm{H}$-bonds such as those in 1B or in azoline forms such as 1A, with which they are in equilibrium. These particles are bonded by a carbene transfer from the alcohol component to the activated ester carbon atom and accept the leaving molecule of alcohol.

\section{Conclusions}

As a consequence of the foregoing, a highly efficient catalysis by mono-, bis- and polyheterocyclic and carbocyclic carbenes was observed for the transesterification reaction when carried out in an excess of alcohol. Furthermore, the TON and TOF indices were found to exceed significantly those of the known catalytic effect of carbenes that have close to stoichiometric quantities of the reactants in the presence of molecular sieves. They also exceed those of the known process by two orders of magnitude in an excess of 
alcohol. The possibility of using polymer $\mathbf{1 1}$ with high efficiency to produce biodiesel fuel has in fact been demonstrated in an experiment on sunflower oil.

\section{Experimental Section}

\section{General information}

The ${ }^{1} \mathrm{H}$ NMR and ${ }^{13} \mathrm{C}$ NMR spectra were recorded using a Bruker Avance II 400 spectrometer $\left(400 \mathrm{MHz}\right.$ for ${ }^{1} \mathrm{H}$ NMR spectra and $100 \mathrm{MHz}$ for ${ }^{13} \mathrm{C}$ NMR spectra) or Gemini 200 spectrometer in $\mathrm{DMSO}-\mathrm{d}_{6}$ or $\mathrm{CDCl}_{3}$ solutions or in the solid state.

The ${ }^{1} \mathrm{H}$ NMR and ${ }^{13} \mathrm{C}$ NMR chemical shifts are reported relative to those of tetramethylsilane (TMS) (solution) and sodium 2,2-dimethyl-2-silapentan-5-sulfonate (DSS) (solid state). The thin-layer chromatography was performed on silica gel with chloroform or a $10: 1$ mixture of chloroform and methanol as an eluent, followed by development with iodine. All elemental analyses were carried out at the Analytical Laboratory of the Litvinenko Institute of Physical Organic and Coal Chemistry.

The molecular characteristics of the oligomers and polymers were studied on a Du Pont device for liquid chromatography that was equipped with a set of bimodal columns Zorbax PSM-100, and 1000, each of which can give a linear calibration in the molecular weight range $102-106$. The chromatograph was calibrated with a polystyrene standard Du Pont PS with molecular weights of $M_{w} 1,000$ and 50,000 ( $\left.M_{w} / M_{n} 1.01\right)$ along with a sample of the known salt $\mathbf{2 a} \cdot \mathbf{H C l O}$. The polymer yield from the column was found by a UV sensor that was tuned to a wavelength of $282 \mathrm{~nm}$.

3,3'-Dimethyl-1,4-butylenedi-(1-imidazolium) perchlorate $\left(8 \mathrm{a} \cdot 2 \mathrm{HClO}_{4}\right)$. To a solution of 1,4-bis-(1imidazolyl)butane $8 \mathrm{~A}\left(\mathrm{X}=\left(\mathrm{CH}_{2}\right)_{4}\right)(0.3 \mathrm{~g}, 1.58 \mathrm{mmol})$ in acetonitrile $(2 \mathrm{~mL})$ dimethyl sulfate $(0.4 \mathrm{~g}, 3.16 \mathrm{mmol})$ was added upon stirring. The reaction mixture was heated to reflux for $4 \mathrm{~h}$, diluted with acetonitrile $(5 \mathrm{~mL})$, and sodium perchlorate $(0.39 \mathrm{~g}, 3.16 \mathrm{mmol})$ was added thereby forming a precipitate of sodium methyl sulfate that was filtered off. The mother liquor was concentrated to $2 \mathrm{~mL}$ and the perchlorate 8 a was precipitated by diethyl ether $(10 \mathrm{~mL})$. Yield $0.5 \mathrm{~g}(76 \%)$. Mp $86-88{ }^{\circ} \mathrm{C}$ (acetonitrile-diethyl ether). ${ }^{1} \mathrm{H} \mathrm{NMR} \mathrm{(400MHz,} \mathrm{DMSO-}$ $\left.\mathrm{d}_{6}\right), \delta_{\mathrm{H}}: 1.76\left(4 \mathrm{H}, \mathrm{s}, \mathrm{CH}_{2} \mathrm{C}\right), 3.84\left(6 \mathrm{H}, \mathrm{s}, \mathrm{CH}_{3} \mathrm{~N}\right), 4.19\left(4 \mathrm{H}, \mathrm{s}, \mathrm{CH}_{2} \mathrm{~N}\right), 7.71\left(4 \mathrm{H}, \mathrm{d}, J 9.6 \mathrm{~Hz}, \mathrm{C}^{4,5} \mathrm{H}\right), 9.05\left(2 \mathrm{H}, \mathrm{s}, \mathrm{C}^{2} \mathrm{H}\right)$. Anal. Calcd for $\mathrm{C}_{12} \mathrm{H}_{20} \mathrm{Cl}_{2} \mathrm{~N}_{4} \mathrm{O}_{8}$ (419.22): $\mathrm{C} 34.38, \mathrm{H} 4.81, \mathrm{Cl} 16.91, \mathrm{~N} 13.36$. Found: $\mathrm{C} 34.47, \mathrm{H} \mathrm{4.73,} \mathrm{Cl} 16.84, \mathrm{~N}$ $13.40 \%$.

\section{3,3'-Dimethyl-1,4-xylylenedi-(1-imidazolium) perchlorate $\left(8 \mathrm{~b} \cdot 2 \mathrm{HClO}_{4}\right)$}

a) (1,4-Xylylene)-1,1'-diimidazole (8B, $\mathrm{X}=\mathrm{CH}_{2} \mathrm{C}_{6} \mathrm{H}_{4} \mathrm{CH}_{2}$ ). To a reaction mixture containing imidazole (1.55 g, $22.8 \mathrm{mmol})$, sodium hydroxide $(6.8 \mathrm{~g}, 170 \mathrm{mmol})$, triethylbenzylammonium chloride $(0.26 \mathrm{~g}, 1.14 \mathrm{mmol})$ and water $(7 \mathrm{~mL})$, a solution of 1,4-xylylene dichloride $(2 \mathrm{~g}, 11.4 \mathrm{mmol})$ in acetonitrile $(10 \mathrm{~mL}) \mathrm{was}$ added portionwise upon stirring. The mixture was stirred at $50 \stackrel{\circ}{\mathrm{C}}$ for $7 \mathrm{~h}$ thus forming the solid. After cooling, the reaction mixture was treated with water $(50 \mathrm{~mL})$. The precipitate was filtered off, washed with water $(50 \mathrm{~mL})$ and dried. Yield $2.3 \mathrm{~g}(85 \%)$. Mp $134-136{ }^{\circ} \mathrm{C}$ (toluene). ${ }^{1} \mathrm{H}$ NMR $\left(400 \mathrm{MHz}, \mathrm{DMSO}-\mathrm{d}_{6}\right), \delta_{\mathrm{H}}: 5.10\left(4 \mathrm{H}, \mathrm{s}, \mathrm{CH}_{2} \mathrm{~N}\right)$, $6.88\left(2 \mathrm{H}, \mathrm{s}, \mathrm{C}^{4,5} \mathrm{H}\right), 7.07\left(2 \mathrm{H}, \mathrm{s}, \mathrm{C}^{4,5} \mathrm{H}\right), 7.13 \mathrm{~m}(4 \mathrm{H}, \mathrm{Ar}), 7.52\left(2 \mathrm{H}, \mathrm{s}, \mathrm{C}^{2} \mathrm{HN}\right)$. The product $8 \mathrm{~B}$ was identical to that reported $^{27}$ from imidazole and 1,4-xylylene dichloride in the presence of $\mathrm{NaH}$ in DMF.

b) 3,3'-Dimethyl-1,4-xylylenedi-(1-imidazolium) perchlorate $\left(\mathbf{8 b} \cdot \mathbf{2} \mathbf{H C l O}_{4}\right)$. To a solution of $(1,4-x y l y l e n e)-1,1 '-$ diimidazole 8 B $(0.84 \mathrm{~g}, 3,36 \mathrm{mmol})$ in acetonitrile $(20 \mathrm{~mL})$ dimethyl sulfate $(0.85 \mathrm{~g}, 6.72 \mathrm{mmol})$ was added portionwise upon cooling, stirred additionally for $20 \mathrm{~min}$ at room temperature and then heating to reflux for $4 \mathrm{~h}$. The solvent was evaporated, the oily product was dissolved in hot water, a small amount of activated charcoal was added, and the solution was filtered. Sodium perchlorate $(0.82 \mathrm{~g}, 6.72 \mathrm{mmol})$ was added to the 
filtrate, and the precipitate formed was filtered off. Yield $0.93 \mathrm{~g}$ (59\%). Mp 222-225 ${ }^{\circ} \mathrm{C}$ (water). ${ }^{1} \mathrm{H} \mathrm{NMR}$ $\left(400 \mathrm{MHz}, \mathrm{DMSO}-\mathrm{d}_{6}\right), \delta_{\mathrm{H}}: 3.86\left(6 \mathrm{H}, \mathrm{s}, \mathrm{CH}_{3} \mathrm{~N}\right), 5.43\left(4 \mathrm{H}, \mathrm{s}, \mathrm{CH}_{2} \mathrm{~N}\right), 7.48(4 \mathrm{H}, \mathrm{s}), 7.69(2 \mathrm{H}, \mathrm{s}), 7.75(2 \mathrm{H}, \mathrm{s})(\mathrm{Ar}), 9.18$, $9.23\left(2 \mathrm{H}, \mathrm{s}, \mathrm{C}^{2} \mathrm{H}\right)$. Anal. Calcd for $\mathrm{C}_{16} \mathrm{H}_{20} \mathrm{Cl}_{2} \mathrm{~N}_{4} \mathrm{O}_{8}$ (467.26): $\mathrm{C} 41.13, \mathrm{H} 4.31, \mathrm{Cl} 15,17, \mathrm{~N}$ 11.99. Found: $\mathrm{C} 41.04, \mathrm{H}$ 4.39, $\mathrm{Cl} 15.28, \mathrm{~N} 12.02 \%$.

Poly- $\alpha, \alpha^{\prime}-(\mathbf{1}, 4-x y l y l e n e)-4,4 '-d i p y r i d i n i u m ~ p e r c h l o r a t e ~\left(9 \cdot 2 \mathbf{H C l O}_{4}\right)$. The mixture of 4,4'-dipyridyl $(1,35 \mathrm{~g}, \mathbf{8 , 6 5}$ $\mathrm{mmol}$ ) and 1,4-xilylene dichloride $(1.51 \mathrm{~g}, 8.65 \mathrm{mmol})$ was heated at $120{ }^{\circ} \mathrm{C}$ in a melt for $1 \mathrm{~h}$. DMF $(5 \mathrm{~mL}) \mathrm{was}$ added and heated at $120{ }^{\circ} \mathrm{C}$ for $8 \mathrm{~h}$. The precipitate was filtered off, washed with DMF (5 mL) and diethyl ether $(20 \mathrm{~mL})$. The chloride salt was dissolved in water, the solution was treated with activated carbon, filtered and treated with sodium perchlorate $(2.2 \mathrm{~g}, 18 \mathrm{mmol})$. Polydipyridinium perchlorate $\mathbf{9} \cdot \mathbf{2} \mathbf{H C l O}_{\mathbf{4}}$ was filtered off and dried at $120{ }^{\circ} \mathrm{C}$. Yield $2.8 \mathrm{~g}(71 \%)$. Mp > $300{ }^{\circ} \mathrm{C}$. ${ }^{1} \mathrm{H}$ NMR $\left(400 \mathrm{MHz}, \mathrm{DMSO}-\mathrm{d}_{6}\right), \delta_{\mathrm{H}}: 5.95\left(4 \mathrm{H}, \mathrm{s}, \mathrm{CH}_{2} \mathrm{~N}\right), 7.70$, $8.02(4 \mathrm{H}, \mathrm{s}), 8.64,8.73,8.87(4 \mathrm{H}, \mathrm{s})(\mathrm{Ar}), 9.33,9.47(4 \mathrm{H}, \mathrm{s})(\underline{\mathrm{C}-2-\mathrm{HN}})$. Anal. Calcd for $\left(\mathrm{C}_{18} \mathrm{H}_{16} \mathrm{Cl}_{2} \mathrm{~N}_{2} \mathrm{O}_{8}\right)_{\mathrm{n}}(459.24): \mathrm{C}$ 47.08, H 3.51, Cl 15.44, N 6.10. Found: C 47.23, H 3.44, Cl 15.24, N $6.20 \%$

\section{Poly-[ $\left.\alpha, \alpha^{\prime}-1,4-x y l y l e n e-1,4-d i-(1-i m i d a z o l i u m-3,3 '-d i y l) b e n z e n e\right]$ perchlorate $\left(10 \cdot 2 \mathrm{HClO}_{4}\right)$.}

a) 1,4-Phenylene-1,1'-diimidazole (10A). To a solution of 1,4-dibromobenzene (5 g, $21 \mathrm{mmol}$ ) and anhydrous imidazole $(3.6 \mathrm{~g}, 53 \mathrm{mmol})$ in dimethylsulfoxide $(25 \mathrm{~mL})$ potassium carbonate $(7.31 \mathrm{~g}, 53 \mathrm{mmol})$ and copper(II) oxide $(0.42 \mathrm{~g}, 5,3 \mathrm{mmol})$ were added. The reaction mixture was heated at $150{ }^{\circ} \mathrm{C}$ for $50 \mathrm{~h}$ with stirring. The product together with the catalyst was treated with water $(100 \mathrm{~mL})$, the precipitate formed was filtered off and washed with water $(30 \mathrm{~mL})$. The product was separated from the catalyst by extraction with chloroform. The solution was filtered through a thin layer of silica gel (the eluent is chloroform-methanol, 5:1) and was evaporated. Yield $3 \mathrm{~g}(68 \%)$. Mp $206-208{ }^{\circ} \mathrm{C}$ (benzene). ${ }^{1} \mathrm{H}$ NMR $\left(400 \mathrm{MHz}, \mathrm{CDCl}_{3}\right), \delta_{\mathrm{H}}: 7.16\left(2 \mathrm{H}, \mathrm{s}, \mathrm{C}^{4,5} \mathrm{H}\right), 7.82$ $\left(2 \mathrm{H}, \mathrm{s}, \mathrm{C}^{4,5} \mathrm{H}\right), 7.83(4 \mathrm{H}, \mathrm{s}, \mathrm{Ar}), 7.52\left(2 \mathrm{H}, \mathrm{s}, \mathrm{C}^{2} \mathrm{HN}\right)$. Anal. Calcd for $\mathrm{C}_{12} \mathrm{H}_{10} \mathrm{~N}_{4}$ (210.24): C 68.56, H 4.79, N 26.65. Found: $\mathrm{C} 68.50, \mathrm{H} 4.87, \mathrm{~N} 26.63 \%$. The product $10 \mathrm{~A}$ was identical to that obtained from 1,4-dibromobenzene, imidazole, $\mathrm{K}_{2} \mathrm{CO}_{3}$ and $\mathrm{CuSO}_{4}$ without a solvent. ${ }^{28}$

b) Poly-[ $\alpha, \alpha^{\prime}-1,4-x y l y l e n e-1,4-d i-\left(1-i m i d a z o l i u m-3,3^{\prime}\right.$-diyl)benzene] perchlorate $\left(\mathbf{1 0} \cdot 2 \mathrm{HClO}_{4}\right)$. A solution of 1,4-phenylene-1,1'-diimidazole $10 \mathrm{~A}(0.5 \mathrm{~g}, 2.38 \mathrm{mmol})$ and 1,4-xylylene dichloride $(0.42 \mathrm{~g}, 2.38 \mathrm{mmol})$ in DMF $(2 \mathrm{~mL})$ was refluxed for $2 \mathrm{~h}$. The precipitate was formed after 10 min of refluxing. The product was filtered off, washed with DMF $(3 \mathrm{~mL})$ and diethyl ether $(15 \mathrm{~mL})$. It was dissolved in water $(20 \mathrm{~mL})$ and added an equimolar amount of sodium perchlorate. The precipitate of polyimidazolium perchlorate $\mathbf{1 0} \cdot \mathbf{2} \mathbf{H C l O}_{4}$ was filtered off and dried at 120 으. Yield $1.22 \mathrm{~g}(100 \%)$. Mp > $300{ }^{\circ} \mathrm{C} .{ }^{1} \mathrm{H}$ NMR $\left(400 \mathrm{MHz}, \mathrm{DMSO}-\mathrm{d}_{6}\right), \delta_{\mathrm{H}}: 5.57\left(4 \mathrm{H}, \mathrm{s}, \mathrm{CH}_{2} \mathrm{~N}\right), 7.65$ $(4 \mathrm{H}, \mathrm{s}), 8.14(4 \mathrm{H}, \mathrm{s})(\mathrm{Ar}), 8.07(2 \mathrm{H}, \mathrm{s}), 8.44(2 \mathrm{H}, \mathrm{s})\left(\mathrm{C}^{4,5}\right), 10.11\left(2 \mathrm{H}, \mathrm{s}, \mathrm{C}^{2} \mathrm{H}\right)$. Anal. Calcd for $\left(\mathrm{C}_{20} \mathrm{H}_{18} \mathrm{Cl}_{2} \mathrm{~N}_{4} \mathrm{O}_{8}\right)_{\mathrm{n}}$ (513.29): C 46.80, H 3.53, Cl 13.81, N 10.92. Found, \%: C 46.63, H 3.54, Cl 14.01, N 10.88.

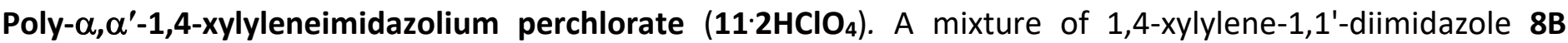
$(0.31 \mathrm{~g}, 1.26 \mathrm{mmol})$ and 1,4-xylylene dichloride $(0.22 \mathrm{~g}, 1.26 \mathrm{mmol})$ was heated in a melt at 150 o $\mathrm{C}$ for $1 \mathrm{~h}$. DMF (2 mL) was added and heated at 150 으 for $8 \mathrm{~h}$. The reaction mixture was diluted with diethyl ether and the solvent was decanted. The chloride salt was dissolved in water $(15 \mathrm{~mL})$ and treated with an excess amount of sodium perchlorate $(0.17 \mathrm{~g}, 1.4 \mathrm{mmol})$. The precipitate formed was filtered off and dried at $120 \cong \mathrm{C}$. Yield 0.5 g (74 \%). Mp $256-258^{\circ} \mathrm{C}$ (toluene). ${ }^{1} \mathrm{H}$ NMR (400MHz, DMSO-d 6$), \delta_{H}: 5.44\left(4 \mathrm{H}, \mathrm{s}, \mathrm{CH}_{2} \mathrm{~N}\right), 7.49(4 \mathrm{H}, \mathrm{m}, \mathrm{Ar}), 7.78$ $\left(2 \mathrm{H}, \mathrm{s}, \mathrm{C}^{4,5} \mathrm{H}\right), 9.37\left(1 \mathrm{H}, \mathrm{s}, \mathrm{C}^{2} \mathrm{HN}\right)$. Anal. Calcd for $\left(\mathrm{C}_{11} \mathrm{H}_{11} \mathrm{ClN}_{2} \mathrm{O}_{4}\right)_{2 \mathrm{n}}(270.57)$ : C 48.81, H 4.10, Cl 13.10, N 10.35 . Found, \%: C 48.82, H 4.19, $\mathrm{Cl}$ 13.02, N 10.34. According to the liquid chromatography data $\mathrm{M}_{\mathrm{w}} 68800 ; \mathrm{M}_{\mathrm{n}}$ 63100; $M_{w} / M_{n}=1.09 ; n_{\text {aver }}=257$.

\section{Procedure for catalytic measurements.}

The catalytic transesterification reaction of ethyl benzoate to methyl benzoate with carbenes 1-11 and onium alkoxides 12,13 were carried out in an anhydrous methanol solution (using a molar ratio of ester-methanol of 1:9 or 1:18). Molecular sieves were not used in this process. 
To a solution of ethyl benzoate $(3.15 \mathrm{~mL}, 22 \mathrm{mmol})$ in a methanolic solution $(8 \mathrm{~mL})$ of potassium methoxide $(0.616 \mathrm{~g}, 0.0088 \mathrm{mmol})$ a salt precatalyst $(0.0088 \mathrm{mmol})$ was added and stirred for $4 \mathrm{~h}$ at room temperature. Diethyl ether $(30 \mathrm{~mL})$ was added to the reaction solution, the organic layer was washed with water $(3 \times 20 \mathrm{~mL})$, separated and dried with anhydrous sodium sulfate. The ether was evaporated and the residue was distilled in a vacuum. The distillate was analyzed by ${ }^{1} \mathrm{H}$ NMR spectroscopy on the contents of methyl benzoate and ethyl benzoate $\left(\delta \mathrm{CH}_{3} \mathrm{O} 3.85\right.$ ppm, ethyl benzoate $\delta \mathrm{CH}_{3} \mathrm{C} 1.34$ ppm and $\delta \mathrm{CH}_{2} \mathrm{C} 4.34 \mathrm{ppm}$ in $\left.\mathrm{CDCl}_{3}\right)$.

\section{Procedure for the preparation of the sunflower biodiesel fuel}

The sunflower oil has been preliminary dried upon stirring with $\mathrm{CaH}_{2}$ in hexane for a night. The polymeric salt $11 \cdot 2 \mathrm{HClO}_{4}\left(2,66 \mathrm{mg}, 9,84.10^{-3} \mathrm{mmol}, 0.033 \mathrm{~mol} \%\right.$ to one ester function of oil) was added to a solution of stoichiometric amount of potassium methoxide $\left(0,689 \mathrm{mg}, 9,84.10^{-3} \mathrm{mmol}\right)$ in anhydrous methanol $(6 \mathrm{~mL})$ and stirred for $10 \mathrm{~min}$. The obtained solution was added to a solution of anhydrous sun flower oil (10 g) in anhydrous methanol $(18 \mathrm{~mL})$ and stirred at room temperature $\left(23^{\circ} \mathrm{C}\right)$ for $4 \mathrm{~h}$. Diethyl ether $(30 \mathrm{~mL})$ was added to the reaction solution, the organic layer was washed with water $(3 \times 20 \mathrm{~mL})$, separated and dried with anhydrous sodium sulfate. The ether was evaporated and the residue was distilled in a vacuum up to dryness collecting a fraction b.p. $166-172{ }^{\circ} \mathrm{C} / 2 \mathrm{~mm} \mathrm{Hg}$ as a colorless mobile liquid. Yield $7.75 \mathrm{~g}$ ( $88 \%$ according to the ester function contents in oil $2.98 \mathrm{mmol} / 1 \mathrm{~g}$ that corresponds to a saponification number $167 \mathrm{mg} / 1 \mathrm{~g})$. Contains predominantly methyl esters of oleic and linoleic acids. ${ }^{1} \mathrm{H} N M R\left(400 \mathrm{MHz}, \mathrm{CDCl}_{3}\right), \delta_{\mathrm{H}}: 0.87\left(3 \mathrm{H}, \mathrm{s}, \mathrm{CH}_{3} \mathrm{C}\right), 1.24$ $\left(16 \mathrm{H}, \mathrm{s}, \mathrm{CH}_{2} \mathrm{C}\right), 1.61\left(2 \mathrm{H}, \mathrm{m}, \mathrm{CH}_{2} \mathrm{C}\right), 2.02\left(3 \mathrm{H}, \mathrm{m}, \mathrm{CH}_{2} \mathrm{C}\right), 2.28\left(2 \mathrm{H}, \mathrm{t}, \mathrm{CH}_{2} \mathrm{C}, \mathrm{J}\right.$ 7,6 Hz), $2.75\left(1 \mathrm{H}, \mathrm{dd}, \mathrm{CH}_{2} \mathrm{C}, \mathrm{J} 6.0 \mathrm{~Hz}\right.$, methyl linoleate, $\left.\mathrm{CH}_{2}-\mathrm{CH}=\right), 3.64\left(3 \mathrm{H}, \mathrm{s}, \mathrm{CH}_{3} \mathrm{O}\right), 5.33(3 \mathrm{H}, \mathrm{m}, \mathrm{CH}=\mathrm{CH})$.

\section{Acknowledgements}

We thank the Ukrainian Academy of Sciences for financial support (grant No. III-02-2015), and the generous financial support provided by the Robert A. Welch Foundation (grant F-0003) (A.H.C.).

\section{Supplementary Material}

Supplementary data to this article can be found online. These data include basic methods and schemes for the preparation of the known carbenes and precarbenes used in the work, and ${ }^{1} \mathrm{H}$ NMR spectra of the synthesized compounds.

\section{References}

1. Mathieu, J.; Panico, R.; Weill-Raynal, J. L'amenagement fonctionnel en synthese organique. Hermann, 1978.

2. Grasa, G. A.; Kissling, R. M.; Nolan, S. P. Org. Lett. 2002, 4, 3583-3586. http://dx.doi.org/110.1021/ol0264760

.3. Nyce, G. W.; Lamboy, J. A.; Connor, E. F.; Waymouth, R. M.; Hedrick, J. L. Org. Lett. 2002, 4, 3587-3590. http://dx.doi.org/10.1021/ol0267228

4. Grasa, G. A.; Gveli, T.; Singh, R.; Nolan, S. P. J. Org. Chem. 2003, 68, 2812-2819. http://dx.doi.org/10.1021/jo0267551

.5. Connor, E. F.; Nyce, G. W.; Myers, M.; Möck, A.; Hedrick, J. L. J. Am. Chem. Soc. 2002, 124, 914-915. http://dx.doi.org/10.1021/ja0173324

6. Singh, R.; Kissling, R. M.; Letellier, M.-A.; Nolan, S.P. J. Org. Chem. 2004, 69, 209-212. http://dx.doi.org/10.1021/jo035431p 
7. Kano, T.; Sasaki, K.; Maruoka, K. Org. Lett. 2005, 7, 1347-1349. http://dx.doi.org/10.1021/ol050174r

.8. Ma, Y.; Wie, S.; Lan, J.; Wang, J.; Xie, R.; You, J. J. Org. Chem. 2008, 73, 8256-8264. http://dx.doi.org/10.1021/jo801349d

9. Korotkikh, N. I.; Shvaika, O. P. Carbene and carbene complex catalysis of organic reactions, DonNU: Donetsk (Ukraine), 2013 (ukr.).

10. Korotkikh, N. I.; Shvaika, O. P. Organic reactions catalysis by carbenes and metal carbene complexes. LAP Lambert Academic Publishing, Saarbrucken, 2015 (eng.).

11. Beall, L.S.; Padwa R. In Advances in Nitrogen Heterocycles; C.J.Moody Ed.; JAI Press Inc., 1998; Vol. 3, p 117-158.

12. Korotkikh, N.I.; Glinyanaya, N. V.; Cowley, A. H.; Moore, J. A.; Knishevitsky, A.V.; Pekhtereva, T.M.; Shvaika, O.P. Arkivoc 2007, (xvi), 156-172.

13. Korotkikh, N.I.; Cowley, A.H.; Moore, J.A.; Glinyanaya, N.V.; Panov, I.S.; Rayenko, G.F.; Pekhtereva, T.M.; Shvaika, O.P. Org. Biomol. Chem. 2008, 6, 195-199.

http://dx.doi.org/10.1039/b712885a

14. Korotkikh, N.I.; Kiselyov, A.V.; Rayenko, G.F.; Oliynik, M.M.; Shvaika, O.P. Rep. Ukr. Acad. Sci. 2003, 6, 142-146 (ukr.).

15. Kiselyov, A.V.; Korotkikh, N.I.; Cowley, A.H.; Moore, J.A.; Pekhtereva, T.M.; Shvaika, O.P. Arkivoc 2008, (xv), 329-342.

16. Arduengo, A.J.; Harlow, R.L.; Kline, M. J. Amer. Chem. Soc. 1991, 113, 361.

http://dx.doi.org/10.1021/ja00001a054

17. Arduengo, A.J. U.S. Patent 5104993, 1992.

18. Arduengo, A.J. U.S. Patent 5162482, 1992.

19. Knishevitsky, A.V. Diss. Cand. Chem. Sci., IPOCC, Donetsk, Ukraine, 2009.

20. Korotkikh, N.I.; Rayenko, G.F.; Shvaika, O.P. Rep. Ukr. Acad. Sci. 2000, 2, 135-140.

21. Rayenko, G.F.; Korotkikh, N.I.; Pekhtereva, T.M.; Shvaika, O.P. Rus. J. Org. Chem. 2001, 37, $1153-1157$. http://dx.doi.org/10.1023/A:1013148532518

22. Korotkikh, N.I.; Raenko, G.F.; Pekhtereva, T.M.; Shvaika, O.P.; Cowley, A.H.; Jones, J.N. Rus. J. Org. Chem. 2006, 42, 1822-1833.

\section{http://dx.doi.org/10.1134/S1070428006120116}

23. Saberov, V.Sh.; Evans, D.A.; Korotkikh, N.I.; Cowley, A.H.; Pekhtereva, T.M.; Popov, A.F.; Shvaika, O.P. Dalton Trans. 2014, 43, 18117-18122.

http://dx.doi.org/10.1039/c4dt02908a

24. Knishevitsky, A.V.; Korotkikh, N.I.; Pekhtereva, T.M.; Krasnorutsky, I.A.; Shvaika, O.P. Probl. Chem. \& Chem. Technol. 2014, 98, 9-17.

25. Knishevitsky, A. V.; Korotkikh, N. I.; Cowley, A. H.; Moore, J. A.; Vasudevan, K. V.; Pekhtereva, T. M.; Shvaika O. P. Arkivoc 2012, (ii), 60-73.

26. Dorofeenko, N. I.; Zhdanov, Y. A.; Dulenko, V. I.; Krivun, S. V. Perchloric acid and its compounds in organic synthesis. RSU, Rostov/Don, 1965, p 32.

27. Tan, M.X.; Zhang, Y.; Ying, J. Y. Adv. Synth. Catal. 2009, 351, 1390-1394. http://dx.doi.org/10.1002/adsc.200800815

28. Vlahakis, J. Z.; Mitu, S.; Roman, G.; Rodriguez, E. P.; Crandall, I. E.; Szarek, W.A. Bioorg. Med. Chem. 2011, 19, 6525-6542.

http://dx.doi.org/10.1016/j.bmc.2011.06.002 
29. Clavier, H.; Nolan, S. P. Chem. Commun. 2010, 46, 841-861. http://dx.doi.org/10.1039/B922984A

30. Nelson, D. J.; Nolan, S. P. Chem. Soc. Rev. 2013, 42, 6723-6753. http://dx.doi.org/10.1039/C3CS60146C

31. Schuchardt U., Sercheli R., Vargas R. M. J. Braz. Chem. Soc. 1998, 9, 199-210. http://dx.doi.org/10.1590/S0103-50531998000300002

32. Sivasamy A., Cheah K. Y., Fornasiero P., Kemausuor F., Zinoviev S., Miertus S. ChemSusChem, 2009, 2, 278 -300 . http://dx.doi.org/10.1002/cssc.200800253

33. Ejikeme P. M., Anyaogu I. D., Ejikeme C. L., Nwafor N. P., Egbuonu C. A. C., Ukogu K., Ibemesi J. A. E-J. Chem. 2010, 7, 1120-1132. downloads.hindawi.com/journals/jchem/2010/689051.pdf

34. Kumar A., Osembo S. O., Namango S. S., Kiriamiti K. H. Proceedings of the 2012 Mechan. Engineer. Confer. Sustain. Res. Innov., Volume 4, 3rd-4th May 2012. http://citeseerx.ist.psu.edu/viewdoc/download?doi=10.1.1.840.4271\&rep=rep1\&type=pdf

35. Sercheli R., Vargas R. M., Schuchardt U. J. Am. Oil Chem. Soc. 1999, 76, 1207-1210. http://dx.doi.org/10.1007/s11746-999-0095-2

36. Bromberg L., Fasoli E., Alvarez M., Hatton T. A., Barletta G. L. React. \& Funct. Polym. 2010, 70, $433-441$. http://dx.doi.org/10.1016/j.reactfunctpolym.2010.04.003

37. Nowicki J., Muszyński M., Gryglewicz S. J. Chem. Technol. .Biotechnol. 2014, 89, 48-55. http://dx.doi.org/10.1002/jctb.4114

38. Strukil V., Leks`ic E., Mes`trovic E., Eckert-Maksic M. Aust. J. Chem. 2014, 67, 1129-1133. http://dx.doi.org/10.1071/CH14233

39. Movassaghi, M.; Schmidt, M. Org. Lett. 2005, 7, 2453-2456. http://dx.doi.org/10.1021/ol050773y

40. Korotkikh, N. I.; Saberov, V. Sh.; Glinyanaya, N. V.; Marichev, K. A.; Kiselyov, A. V.; Knishevitsky, A. V.; Rayenko, G. F.; Shvaika, O. P. Chem. Het. Comp. 2013, 49, 19-46.

http://dx.doi.org/10.1007/s10593-013-1230-4 